\title{
https://doi.org/10.46813/2021-134-149 \\ MEASUREMENT OF THE LOCAL ELECTRON TEMPERATURE IN SELF-COMPRESSED PLASMA STREAM
}

\author{
D.G. Solyakov ${ }^{1,2}$, Yu.Ye. Volkova ${ }^{1,2}$, I.E. Garkusha ${ }^{1,2}$, A.K. Marchenko ${ }^{1}$, M.S. Ladygina, \\ V.V. Staltsov ${ }^{1}$, Yu.V. Petrov ${ }^{1}$, V.V. Chebotarev ${ }^{1}$, T.M. Merenkova ${ }^{1}$, V.A. Makhlai ${ }^{1,2}$, \\ D.V. Yeliseyev ${ }^{1}$ \\ ${ }^{1}$ National Science Center "Kharkov Institute of Physics and Technology", Kharkiv, Ukraine; \\ ${ }^{2}$ V.N. Karazin Kharkiv National University, Kharkiv, Ukraine \\ E-mail: solyakov@ipp.kharkov.ua
}

The local electron temperature measurements with the double electric probe in the compression zone are presented. Electric probes make it possible to measure the electron temperature with a reasonably good spatial resolution. Double electric probe application for electron temperature measurements in the dense self-compressed plasma stream is discussed. We have shown experimentally that the electric probe operates in a diffusion regime.

PACS: 52.40.Hf; 52.70

\section{INTRODUCTION}

High-density and high-power plasma streams, namely self-compressed plasma streams generated in a quasistationary mode, have many applications in different areas of studies, including plasma-surface interaction, astrophysics, electric propulsion, etc. Professor A.I. Morozov formulated the main principles of the quasistationary plasma acceleration and the self-compressed plasma streams [1]. Theoretically, it is possible to reach high density and temperature values in compression zone forms in a self-compressed plasma stream generated by a magnetoplasma compressor. The plasma density in the compression zone can be up to $10^{18} \ldots 10^{19} \mathrm{~cm}^{-3}$ and temperature up to a few kiloelectronvolt. In many previous experiments [2 - 7], plasma streams with a plasma density of $10^{18} \mathrm{~cm}^{-3}$ were obtained. Various diagnostic methods, such as wide-field interferometry and Stark broadening of different spectral lines, were applied for density measurements. All these methods cannot give a local value of electron density in the plasma stream.

In many previous experiments, electron temperature was estimated based on the ratio of the intensities of different spectral lines $[8,9]$ or the pressure balance equation for an azimuthal self-generated magnetic field displaced from the compression zone [7]. Both of these methods do not give a local value of the electron temperature. In the first case, the spectral line intensity was measured along the line of sight. Consequently, the obtained value of the electron temperature was also averaged along the line of sight. In experiments [9], the electron temperature was estimated from the ratio of spectral lines Xe II and Xe III. However, these lines are emitted from the periphery layers of the plasma stream. Therefore, the result corresponds to a periphery layer but not a near-axis region, where the compression zone forms.

Plasma temperature estimated from the pressure balance equation corresponds to the volume of the compression zone in the plasma stream, so this is not a local value at a particular point. Thus, it is averaged for the volume of the compression zone. Moreover, to apply the pressure balance equation for the temperature estimation, the radial distribution of plasma density should be measured first. The value of the plasma density measured from Stark broadening of spectral lines is also averaged along the line of sight.

So, both methods applied in the previous experiments for electron temperature measurements cannot give a local value of electron temperature in the nearaxis region where the compression zone forms.

Electric probes are among the most reliable diagnostic tools among the contact methods used to measure plasma parameters with sufficiently high temporal and spatial resolution in various devices [10 - 16], including tokamaks and stellarators $[17,18]$. Sometimes, when the electron energy distribution function (EEDF) consists of a bi-Maxwellian with well-separated temperatures [17 19], the two temperatures can be obtained by straightline fits on the semi-logarithmic discharge-voltage characteristic.

In this paper, we report our recent experimental results of the measurements of electron temperature locally. We applied double electric probes for these measurements.

This paper is structured as follows: the first section describes the experimental setup and diagnostics system. The second section is devoted to the operation of the double electric probe, followed by the third section that discusses our experimental results. The last section summarizes the main findings.

\section{EXPERIMENTAL DEVICE AND DIAGNOSTICS}

Experiments were performed in the magnetoplasma compressor (MPC) device [5, 10]. The accelerating channel of the MPC used in the present experiments consists of two coaxial copper electrodes. An external electrode (anode) is formed by a solid cylindrical part and a conical part consisting of 12 rods inclined at 7.5 degrees to the axis of the channel. The cylindrical part is $12 \mathrm{~cm}$ in diameter and $14.5 \mathrm{~cm}$ in length. Each rod of the conical part of the anode is $14.7 \mathrm{~cm}$ in length 
and $1 \mathrm{~cm}$ in diameter. Following a similar shape, an internal electrode (cathode) consists of cylindrical and conical parts. A solid cylinder-like part of the cathode is $20.8 \mathrm{~cm}$ in length and $6 \mathrm{~cm}$ in diameter. A $12 \mathrm{~cm}$-long conical part with an outlet diameter of $3 \mathrm{~cm}$ has a hollow at its end, acting as a divertor for impurities from the main plasma flow.

A system of capacitor banks triggered by a vacuum spark gap supplies the MPC discharge. The capacitor system's total capacitance is $90 \mu \mathrm{F}$, with a maximum voltage reaching up to $30 \mathrm{kV}$.

The MPC is installed inside a solenoid that produces an axial magnetic field of up to $0.4 \mathrm{~T}$ in the accelerating channel. The inner diameter and the total length of the solenoid are 15 and $17 \mathrm{~cm}$, respectively [10]. Fig. 1 shows a general view of the entire system, including the solenoid with the MPC accelerating channel inside.

The MPC device operates in a regime with residual gas at different pressures. The working gas is Helium at a pressure of 2 and 10 Torr.

The complete system of the MPC with the solenoid is installed inside the vacuum chamber of $2 \mathrm{~m}$ in length and $40 \mathrm{~cm}$ in diameter.

The diagnostic system included a Rogovsky coil for discharge current measurements, voltage dividers, a set of local magnetic probes for measurements of the spatial distribution of the magnetic field in the plasma stream. The electric probes of a unique design were applied to measure the spatial distributions of the electrical field in the plasma stream.

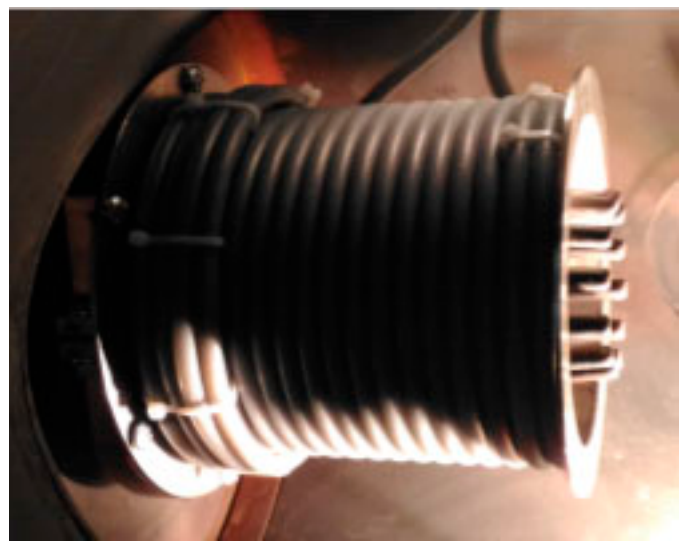

Fig. 1. MPC with a solenoid

A number of double electric probes were used for local electron temperature measurements. The probes are made of molybdenum wire; their non-working surface is shielded with a cylindrical ceramic tube. The diameter of the working surface is $1 \mathrm{~mm}$, and the length is $3 \mathrm{~mm}$. The measuring circuit is isolated from the MPC electrodes and plasma by a sensitive Rogovsky coil. An isolated capacitor bank of $0.05 \mathrm{~F}$ and the maximum voltage of up to $100 \mathrm{~V}$ powers the probes. Fig. 2 presents the general view of the double electric probe.

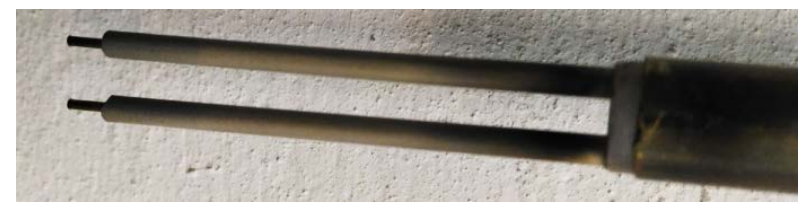

Fig. 2. Doubleprobe general view

\section{DOUBLE ELECTRIC PROBE MODE OF OPERATION}

The results of the double electric probe measurements strongly depend on their mode of operation. So, as the first step, we have to determine the probe mode of operation that depends on plasma density, temperature, and density of neutral atoms. The MPC generates plasma streams of very high parameters. For example, plasma density typically varies from $10^{18} \mathrm{~cm}^{-3}$ in the near-axis region to $10^{15} \mathrm{~cm}^{-3}$ in the plasma periphery layers. Electron temperature ranges from a few electronvolt in the periphery of the plasma stream to several tenths of electronvolt in the compression zone, as follows from the pressure balance equation [5 - 7].

In order to determine the mode of operation of the probe, we have to compare several typical values: $\lambda_{i, e^{-}}$ the length of free path of charged particles; $L_{d}$ - Debye length, and $R_{p}$ - the probe radius. The hierarchy of the characteristic lengths in the plasma stream generated by the MPC becomes

$$
R_{p}>>\lambda_{i, e}>>L_{d}
$$

Another critical parameter for the determination of the probe mode of operation is the ionization length $L_{i}$. In our case, $L_{i}>>\lambda_{i}$. Therefore, the double electric probe works in the diffusion regime [11 - 16]. As it has been shown, in this mode of probe operation, the ion saturation current does not depend on the probe diameter and can be written as

$$
I_{i}=j_{i} \cdot S_{p}=\frac{1}{4} \cdot e \cdot n \cdot \bar{v}_{i} \cdot \frac{\lambda_{i, a}}{R_{p}} \cdot S_{p}=I_{i}^{\text {Langmuir }} \cdot \lambda_{i, a},
$$

where $S_{p}$ - area of the probe electrodes; $j_{i}$ - density of the ion saturation current; $n$ - density; $v_{i}$ - ion velocity; $\lambda_{i, a}$ - the free path length; $I_{i}^{\text {Langmuir }}$ - Langmuir's ion saturation current. Thus, Langmuir's theory can be applied for measurements of the lower level of electron temperature. Taking into account the measured ion saturation current in the diffusion mode of the probe operation, we can experimentally examine the probe mode of operation discussed below.

\subsection{PROBE MODE OF OPERATION AND LIFETIME}

We have designed and constructed the double electric probe with different electrode diameters (1 and $0.3 \mathrm{~mm}$ ). Fig. 3 shows the signals of the ion saturation currents (the probe voltage of $30 \mathrm{~V}$ corresponds to the ion saturation current) for the probe with different electrode diameters.

As we can see from the data obtained, the probe signals for direct and reverse polarity are virtually identical. This result is an immediate experimental confirmation that the double electric probe operates in the diffusion regime.

Considering an electrode of the probe as a target, we expect it to be irradiated under the plasma stream treatment. Apparently, the irradiation depends on the energy density in the plasma stream. As we have discovered in the present experiments, the probe installed at a distance of $3 \mathrm{~cm}$ from the inner MPC electrode probe operates without significant damage during several hundred MPC shots. When the probes are moved from the inner MPC electrode to a distance of $8 \mathrm{~cm}$, the probe elec- 
trodes become destroyed after ten consecutive MPC shots. This experimental result shows that the compression zone, forming in the plasma stream, is shifted away from the MPC electrodes. Therefore, the erosion of the MPC electrodes is reduced, which is of great importance for different MPC applications.

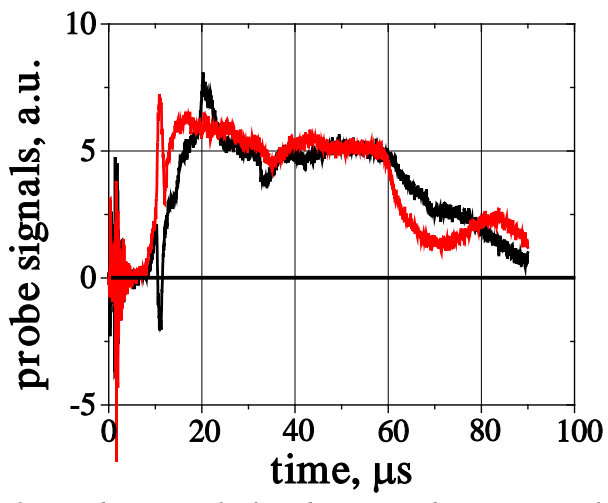

Fig. 3. Probe signals for direct and reverse polarity

\section{EXPERIMENTAL RESULTS AND DISCUSSION}

Experiments have been carried out in the MPC facility under the following experimental conditions: the operation with residual working gas - Helium at a pressure of 2 Torr; the discharge current $I_{d}=400 \mathrm{kA}$; the magnitude of the external longitudinal magnetic field $\left(\mathrm{H}_{\mathrm{z}}\right)$ inside the MPC channel of 0 and $0.26 \mathrm{~T}$.

The typical waveforms of the discharge current, the double electric probe, the azimuthal component of the self-magnetic field $\left(\mathrm{H}_{\varphi}\right)$ in the plasma stream, and the radial component of the electric field $\left(E_{r}\right)$ are shown in Fig. 4.

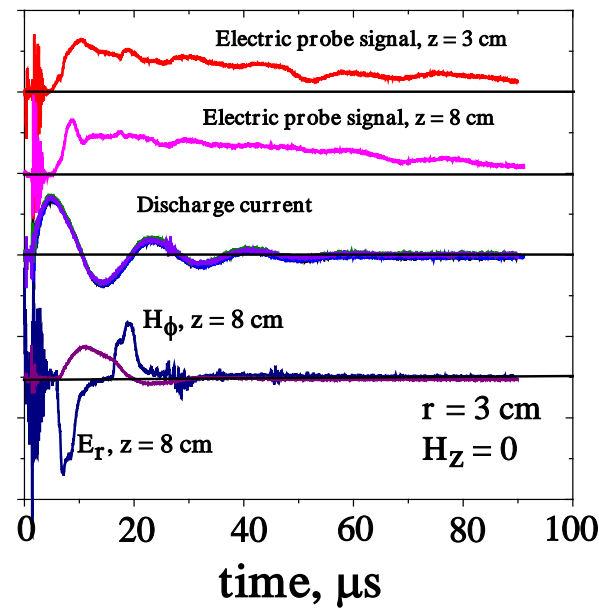

Fig. 4. Waveforms of the discharge current, double electric probe, self-magnetic field $H_{\varphi}$, and radial component of electric field $E_{r}$

The half-period of the discharge current is $10 \mu \mathrm{s}$. The duration of the signals of the self-magnetic field and radial component of the electric field correspond to the discharge duration. Surprisingly, the duration of the electric probe signals is about $70 \ldots 80 \mu \mathrm{s}$. Such a considerable duration of the electric probe signal can be explained by a long lifetime of the plasma stream that flows from the MPC output to the end of the vacuum chamber (the time of flight is about $20 \ldots 30 \mu \mathrm{s}$ ), is reflected from the end flange, and then moves back.
We measured the current-voltage characteristics of the electric probe with a step of the biasing probe voltage of $2 \ldots 4 \mathrm{~V}$ from point to point in space. The statistical spread of the probe signals did not exceed $10 \%$. Special attention was paid to the probe electrode cleanness. Probe electrodes were cleaned by aglow discharge or a high-voltage (up to $100 \mathrm{~V}$ ) short discharge after two working shots.

Fig. 5 illustrates the typical I-V curve of the electric probe measured at a distance of $8 \mathrm{~cm}$ from the inner electrode and a radius of $2 \mathrm{~cm}$ for the discharge time of $10 \mu \mathrm{s}$.

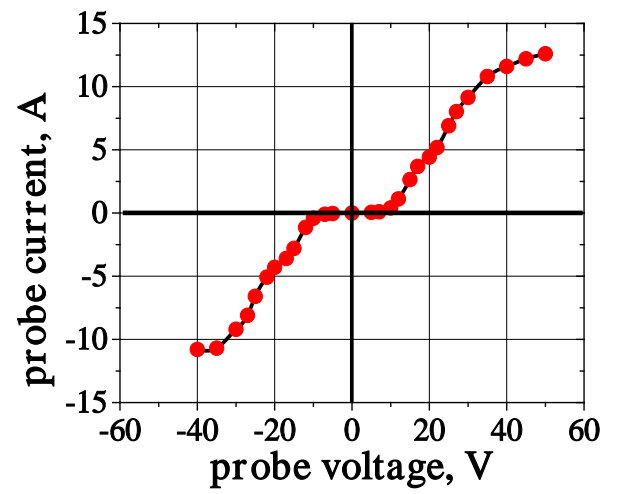

Fig. 5. Typical I-V curves of double electric probe

As we can see, the I-V curve is symmetrical with respect to a zero biasing probe voltage. The probe current reaches saturation at $15 \ldots 40 \mathrm{~V}$ of the voltage applied, depending on the radius and distance from the MPC electrodes.

The current-voltage characteristics of the double electric probe were measured at different spatial positions and MPC mode of operation, with and without an external magnetic field. The semi-logarithmic scale was applied for I-V curves analysis and electron temperature estimation. Fig. 6 shows the typical I-V curve of the electric probe in a semi-logarithmic scale for the periphery layers of the plasma stream $(\mathrm{r}=4 \mathrm{~cm})$ and a distance of $8 \mathrm{~cm}$ from the central electrode.

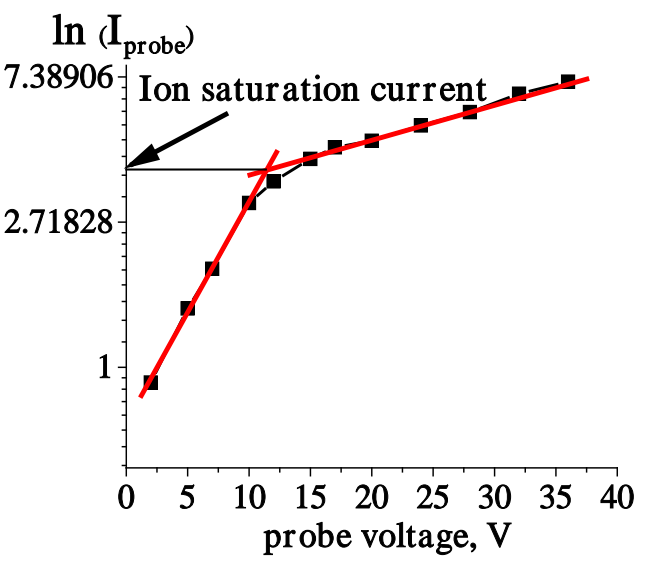

Fig. 6. Probe I-V curve in semi-logarithmic scale

As we can see, the experimental data of the probe current-voltage characteristic in a semi-logarithmic scale fits well on two linear regions with reasonable accuracy. The ion saturation current starts at a probe voltage of $12 \ldots 14 \mathrm{~V}$ for this experimental condition. The transition region of the probe $I-V$ curve for a $0 \ldots 12 \mathrm{~V}$ voltage can be approximated by a linear func- 
tion with reasonable accuracy. This result allows us to suggest that the electron energy distribution function is close to Maxwellian. Therefore, we estimated the electron temperature from Langmuir's theory applying the following equation

$$
T_{e}=\frac{1}{2} \cdot I_{\text {saturation }} \cdot\left[\frac{d I}{d U_{p}}\right]_{U_{p} \rightarrow 0}^{-1},
$$

where $I_{\text {saturation }}$ - the ion saturation current measured by the probe, $U_{p}$ - the probe voltage. We want to point out that this approach underestimates the true value of the ion saturation current. Owing to this fact, the electron temperature is also underestimated with respect to the actual value. Therefore, the double electric probe can be applied to measure the lower level of the electron temperature. Unfortunately, within the framework of the present experiments, we cannot estimate how an actual value of the saturation current differs from its measured value. The reduction ratio depends on the probe position and is presumably smaller in the periphery layers of the plasma stream than in the near-axis region. Electron temperature estimated for the periphery layers of the plasma stream is about $3 \ldots .5 \mathrm{eV}$. There is a good match between these values and those obtained earlier [7] at the flow periphery with spectroscopic methods.

As for electron temperature estimation in the nearaxis region, at a distance of $3 \mathrm{~cm}$ from the cathode and a radius of $1 \mathrm{~cm}$, the electron temperature was about $8 \ldots 12 \mathrm{eV}$. It was not possible to measure the currentvoltage characteristic of the probe at a radius smaller than $2 \mathrm{~cm}$ at $\mathrm{z}=8 \mathrm{~cm}$ due to complete evaporation of the probe working electrodes after 10 MPC shots. However, it was still attainable to conduct the I-V curve measurements at a radius of $2 \mathrm{~cm}$ for this distance. At a radius of $2 \mathrm{~cm}$, the electron temperature was found to be above $15 \mathrm{eV}$. The I-V curve measured in the presence of the axial external magnetic field is shown in Fig. 7.

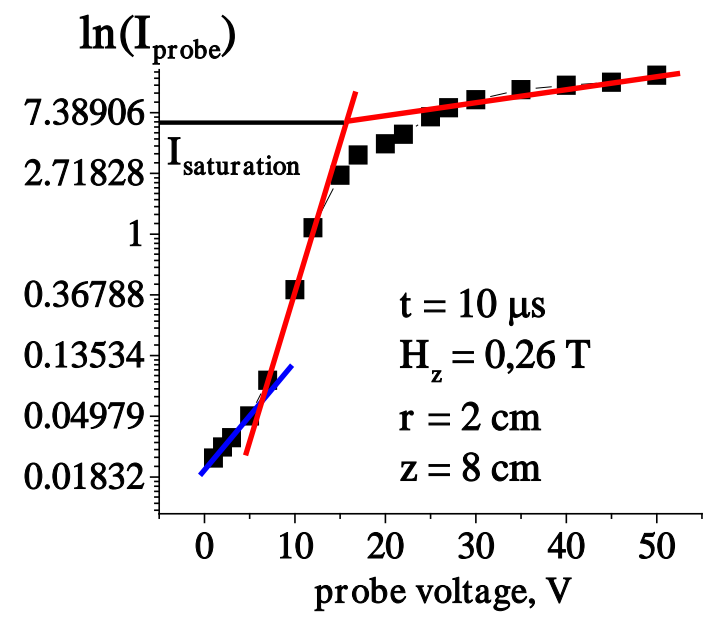

Fig. 7. Double probe I-V curve in semilog scale for discharge time $t=10 \mu$ s, external magnetic field $H_{z}=0.26 \mathrm{~T}$

The transition region of the probe I-V curve (see Fig. 7), when plotted semi-logarithmically vs. the probe voltage, consists of two segments of lines that can be fitted with linear functions. Since such a finding is the indication of the bi-Maxwellian EEDF, it points out two populations of electrons near the compression zone, which have temperatures of $6 \ldots 7$ and $60 \ldots 70 \mathrm{eV}$, re- spectively. The high value of the electron temperature does not contradict ourresults obtained previously [7]. In the above mentioned research, the plasma temperature $T=T_{e}+T_{i}$, averaged along the compression zone with a $2 . .3 \mathrm{~cm}$ radius, was estimated based on the pressure balance equation and reached around $60 \ldots 120 \mathrm{eV}$. For that, the plasma density was determined from the Stark broadening of HeII spectral line [7] and, as we mentioned earlier, averaged along the line of sight. The fact that the electron temperature turned out to be that high in the near-axis region explains the short lifetime of the electric probes.

It has been discovered for the first time that the electron energy distribution is bi-Maxwellian in the MPC mode of operation with an external longitudinal magnetic field applied inside the accelerating channel only. The EEDF in the near-axis region may deviate from a single-Maxwellian distribution and form a bi-Maxwellian one due to various processes related to the formation of the compression zone as well as the presence of the magnetic field. We should emphasize that a more detailed study must be performed to clarify the origin of the bi-Maxwellian EEDF in this mode of the MPC operation.

\section{CONCLUSIONS}

The double electric probe was applied to measure the local value of the electron temperature in the plasma stream generated by the MPC. We have shown that the electric probe works in the diffusion regime at plasma parameters typical for the present experiments. In this mode of operation, the current measured by the probe does not depend on the probe size. It is an important conclusion considering the high value of energy deposition on the working electrodes of a probe leading to their fast evaporation. The value of the ion saturation current measured by the probe turned out to be lower than Langmuir's current due to the attenuation in the near-probe layer. Within the framework of this study, we have not been able to determine the coefficient of this attenuation. Therefore, the lower level of the electron temperature was analyzed. We have experimentally discovered that the electron temperature measured with a double electric probe strongly depends on the MPC mode of operation and probe spatial position. The electron temperature measured by the electric probe in the periphery part of the plasma stream gave figures of approximately $3 \ldots 5 \mathrm{eV}$, which are in good agreement with spectroscopic measurements conducted in our previous studies.

In the near-axis region $(\mathrm{r} \leq 2 \mathrm{~cm})$, the results of the probe measurements showed disagreement with the spectroscopic measurements obtained earlier. At a distance of $3 \mathrm{~cm}$ from the central electrode, the electron temperature was about $8 \ldots 12 \mathrm{eV}$ at $\mathrm{r}=1 \mathrm{~cm}$. At a distance of $8 \mathrm{~cm}$ from the central electrode, the electron temperature at $\mathrm{r}<2 \mathrm{~cm}$ could not be adequately measured due to the fast evaporation of the probe electrodes.

When an external magnetic field is applied inside the MPC channel, the I-V curve shows a bi-Maxwellian EEDF indicating the presence of two populations of electrons with different temperatures in the vicinity of the compression zone. Notably, the high values of electron 
temperature near the compression zone are found to be in good agreement with our previous experiments. The twotemperature Maxwellian EEDF in the compression zone has been discovered for the first time. It might be accounted for by the influence of a magnetic field and different phenomena accompanying the plasma dynamics in this region. Possible causes are of great interest for our future research. Furthermore, the actual EEDF is vital for the understanding of underlying physics.

\section{ACKNOWLEDGEMENTS}

This work has been supported by the Targeted Program of the National Academy of Sciences of Ukraine (NASU) on Plasma Physics № П- 9/24-2020.

\section{REFERENCES}

1. A.I. Morozov. Introduction to Plasma dynamics. M.: "Fizmatlit", 2006.

2. A.K. Vinogradova, A.I. Morozov. Stationary selfcompressed flows // Fizika i primenenie plazmennyh uskoritelej. Minsk, 1974, p. 103-141 (in Russian).

3. P.E. Kovrov, A.P. Shubin. High-current coaxial plasma accelerator in quasy-steady-state regime // Fizika i primenenie plazmennyh uskoritelej. Minsk, 1974, p. 78-102 (in Russian).

4. V.M. Astashynski et al. Choice of operating conditions and plasma parameters of a magnetoplasma compressor // Journal of Engineering Physics. 1992, v. 62(3), p. 386-390.

5. I.E. Garkusha, V.V. Chebotarev, V.I. Tereshin, et al. // Plasma Physics Reports. 2011, v. 37, № 11, p. 948-955.

6. I.E. Garkusha, V.V. Chebotarev, et al. Compression Zone of a Magnetoplasma Compressor as a Source of Extreme UV Radiation // Plasma Physics Reports. 2012, v. 38 (2), p. 110-116.

7. D.G. Solyakov, Yu.V. Petrov, et al. Formation of the Compression Zone in a Plasma Flow Generated by a Magnetoplasma Compressor // Plasma Physics Reports. 2013, v. 39 (12), p. 986-993.

8. A.E. Prinn, B.W. Ricketts, et al. Measurements of temperatures and densities in a continuous flow pinch // $5^{\text {th }}$ European Conf. on Contr. Fusion 1. Grenoble, 1972, p. 54.

9. V.V. Chebotarev, I.E Garkusha, et al. Dynamics of nitrogen and xenon plasma streams generated by MPC device // Problems of Atomic Science and Technology. Series “Plasma Physics”. 2007, № 1, p. 104-106.

10. D.G. Solyakov, Y.E. Volkova, et al. Discharge characteristics in the MPC channel in presence of external longitudinal magnetic field // Problems of Atomic Science and Technology. 2019, № 1, p. 208-211.

11. V.A. Zhovtyansky, E.P. Kolesnikova, et al. Zondovaya diagnostika plotnoj electrodugovoj plasmy // Tezisy dokladov "Enrgoeffektivnost-2012” Institut elektrofiziki i elektroenergetiki RAN. 2012, p. 53-55 (in Russian).

12. F.G. Baksht, G.A. Dyuzhev, et al. The probe measurements in low temperature high ionized plasma // J. Tech. Phys. 1973, v. 43, p. 2574-2583.

13. F.G. Baksht, A.B. Rybakov. To the probe theory in high ionized high pressure plasma // J. Tech. Phys. 1997, v. 67, p. 16-20.

14. V.A. Zhovtyansky. Decay of Inert-Gas-Discharge Plasma in the Expansion Mode // Technical Physics. 2009, v. 54, p. 635-643.

15. V.A. Zhovtyansky, V.V. Kevlich, et al. Proverka primenimosti diffuzionnogo zonda dlya diagnostiki plotnoj plazmy inertnyh gazov // Fizika i tehnika plazmy. Minsk, 1974. v. 1, p. 379-382 (in Russian).

16. F.G. Baksht. To the probe theory in high ionized plasma // J. Tech. Phys. 1973, v. 43, p. 214-217.

17. V.K. Popovet et al. Bi-Maxwellian electron energy distribution function in the vicinity of the last closed flux surface in fusion plasma // Plasma Phys. Control. Fusion. 2015, v. 57, p. 115011.

18. H. Takahashi et al. Influence of the formation of a bi-Maxwellian distribution on volumetric recombining plasma spectroscopy // Phys. Plasmas. 2019, v. 26, p. 033506.

19. V.I. Demidov, S.V. Ratynskaia, K. Rypdal. Electric probes for plasmas: The link between theory and instrument // Review of scientific instruments. 2002, v. 73(10), p. 3409-3439.

Article received 31.05.2021

\section{ИЗМЕРЕНИЕ ЛОКАЛЬНОЙ ЭЛЕКТРОННОЙ ТЕМПЕРАТУРЫ В ПОТОКЕ САМОСЖАТОЙ ПЛАЗМЫ}

Д.Г. Соляков, Ю.Е. Волкова, И.Е. Гаркуша, А.К. Марченко, М.С. Ладыгина, В.В. Стальцов, Ю.В. Петров, В.В. Чеботарёв, Т.Н. Меренкова, В.А. Махлай, Д.В. Елисеев

Представлены результаты измерений локальной электронной температуры двойным электрическим зондом в зоне компрессии. Электрические зонды позволяют измерять температуру электронов с достаточно хорошим пространственным разрешением. Обсуждается применение двойного электрического зонда для измерения электронной температуры в плотном потоке самосжатой плазмы. Экспериментально показано, что электрический зонд работает в диффузионном режиме.

\section{ВИМІРЮВАННЯ ЛОКАЛЬНОЇ ЕЛЕКТРОННОЇ ТЕМПЕРАТУРИ В ПОТОЦІ САМОСТИСНЕНОЇ} ПЛАЗМИ

\section{Д.Г. Соляков, Ю.Є. Волкова, І.Є. Гаркуша, А.К. Марченко, М.С. Ладигіна, В.В. Стальцов, Ю.В. Петров,} В.В. Чеботарьов, Т.М. Меренкова, В.О. Махлай, Д.В. Слісєєв

Наведено результати вимірювань локальної електронної температури подвійним електричним зондом у зоні стиснення. Електричні зонди дозволяють вимірювати температуру електронів з досить високою просторовою роздільною здатністю. Розглянуто застосування подвійного електричного зонда для вимірювання електронної температури в щільному потоці самостисненої плазми. Експериментально показано, що електричний зонд працює в дифузійному режимі. 